\title{
Dialysis-related factors affecting self- efficacy and quality of life in patients on haemodialysis: a cross-sectional study from Palestine
}

\author{
Ibrahim Mousa ${ }^{1}$, Raed Ataba', Khaled Al-ali' ${ }^{1}$ Abdulsalam Alkaiyat ${ }^{2}$ and Sa'ed H. Zyoud ${ }^{3,4,5^{*}}$
}

\begin{abstract}
Background: Chronic kidney disease (CKD) is one of the main public health issues. It increases the morbidity and mortality of patients. Treatment includes multiple aspects such as dialysis and lifestyle modifications. The primary goal of this study was to determine factors associated with self-efficacy and health-related quality of life (HRQoL) among haemodialysis (HD) patients.

Methods: A cross-sectional descriptive correlation study was conducted on CKD patients undergoing HD at 12 different dialysis centres in Palestine. Self-efficacy was assessed by the Self-Efficacy for Managing Chronic Disease Six-Item Scale (SEMCD-6), and HRQoL was assessed using the Five-level EuroQol Five-Dimensions (EQ-5D-5L) tool. Multiple linear regression analysis was carried out to assess the association of factors with each of the SEMCD-6 and HRQoL scale scores.

Results: A total of $283 \mathrm{HD}$ patients were included in the study. A correlation test revealed moderately positive association between the EQ-5D and SEMCD-6 scores $(r=0.497, p$ value $<0.001)$. In multiple linear regression analysis, age, living status, and number of co-morbid diseases were negatively associated with SEMCD-6 scores ( $\beta=-2.66, p=$ $0.016 ; \beta=-5.71, p=0.033 ; \beta=-1.84, p=0.006$, respectively). Furthermore, there is a positive association between educational level and SEMCD-6 score with QoL score $(\beta=0.05, p=0.017 ; \beta=0.01, p<0.001$, respectively), while there is a negative association between the number of co-morbid diseases and QoL score $(\beta=-0.07, p=0.001)$.

Conclusions: This study assessed factors associated with impaired self-efficacy and HRQOL in HD patients. The results show that impaired self-efficacy was associated with the elderly, patients living with family, and patients with a high number of co-morbid diseases. Furthermore, this study found that the worst HRQoL was associated with patients with a low education level, lower levels of self-efficacy, and a high number of co-morbid diseases.
\end{abstract}

Keywords: Chronic kidney disease, Haemodialysis, Self-efficacy for managing chronic disease, Health-related quality of life

\section{Background}

Chronic kidney disease (CKD) is one of the major public health problems worldwide [1]. It is characterised by progressive loss in kidney function that gradually causes end-stage renal disease (ESRD) [2], which requires kidney transplantation or dialysis [3, 4]. ESRD is the last

\footnotetext{
*Correspondence: saedzyoud@yahoo.com; saedzyoud@najah.edu

${ }^{3}$ Poison Control and Drug Information Center (PCDIC), College of Medicine and Health Sciences, An-Najah National University, Nablus 44839, Palestine ${ }^{4}$ Department of Clinical and Community Pharmacy, College of Medicine and Health Sciences, An-Najah National University, Nablus 44839, Palestine Full list of author information is available at the end of the article
}

stage of the National Kidney Foundation Kidney Disease Outcomes Quality [2]. In the last 10 years, the prevalence and frequency of ESRD has risen steadily by $4-8 \%$ per year throughout the world. Diabetes mellitus (DM) is the major predisposing factor for $\operatorname{ESRD}[5,6]$, accounting for nearly $44 \%$ of new cases [6-8]. CKD has a major effect on the individual level by increasing the morbidity and mortality of patients and also increasing healthcare costs and the demand for healthcare services on a national level [1]. With this increasing rate of CKD, increased awareness and understanding of the overall

(c) The Author(s). 2018 Open Access This article is distributed under the terms of the Creative Commons Attribution 4.0 International License (http://creativecommons.org/licenses/by/4.0/), which permits unrestricted use, distribution, and 
CKD burden is needed, which may lead to improvement in the knowledge, trust, and involvement in selfmanaging the disease [9]. Haemodialysis (HD) is the most common method of treatment, with approximately $90.6 \%$ of patients undergoing it. The difficulties faced by these patients are countless and influence their routine and the way they relate, as they often cause emotional difficulty and physical impairment [10]. Treatment of patients with ESRD has multiple aspects in addition to dialysis, as it requires total lifestyle changes that affect the social and psychological state of patients [4].

Self-management of adults with CKD has a positive relation with health outcomes. Perceived disease-related self-efficacy (DSE) is essential to self-managing chronic disease successfully [3]. Recent studies discuss how ESRD patients treated with HD carry out selfmanagement activities in their daily life [11-16]. Patients should follow the treatment recommendations and learn to include them in their life circumstances in order to make CKD progress slowly and to have a stable life [3]. Generally, the concept of self-efficacy involves finding the limit at which the patients can achieve their desired outcomes. An association between self-efficacy and selfmanagement in patients with CKD has been shown in previous researches [11, 17, 18]. HD patients with improved self-efficacy and self-care by empowerment programmes show an increased likelihood to get involved in self-management [19]. Higher perceived self-efficacy scores have shown a significant relation with quality of life (QoL) [6], a higher level of cooperation, self-care, communication, and medication-adherence behaviours [19]. Furthermore, high self-efficacy has an association with good changes in healthcare actions and health status. An improvement in deferent aspects of HD patients has been evidenced with increased self-efficacy, decreased hospitalisations, decreased amputations, control of interdialytic weight gain, and improved QoL in diabetic dialysis patients [11]. In order to attain a better QoL, patients with chronic renal disease should incorporate this goal in their daily life. The index of well-being or QoL is completely different from persons considered healthy, because CKD patients' health objectives concentrate on having a health level that secures an independent life [20].

Chronic kidney disease was ranked the six (3.6\%) as the leading cause of the most burden disease, expressed as a percentage of disability-adjusted life years (DALYs) from reported chronic diseases in the West Bank/ Palestine in 2010 [21]. According to the 2017 annual health report of the Palestinian Ministry of Health [22], there is an increasing number of patients with CKD who become dialysis dependent. The overall number of dialysis patients in the West Bank/Palestine has increased from 1014 patients in 2015 [23] to 1119 patients in 2016 which showed substantial trends in patients requiring haemodialysis [22]. A study by Younis et al. in 2015 [24] assessed the costs of HD in Palestine. The study found that the total cost per HD patient during visits to dialysis centres was an average of US\$16085 per year which covered all medications, laboratory tests, and outpatient visits. The Palestinian government covered almost all of the costs of HD and transplantation [24].

Despite the assessment of self-management and selfefficacy in many studies $[4,9,11-16,19,25-34]$, no studies have been performed to calculate the self-efficacy and QoL of HD patients in Palestine. Although several research has been carried out on HD patients and about CKD in Palestine [35-41], a literature review showed no previous studies on the association between the QoL and self-efficacy among HD patients in Palestine. This is important, because it is thought that religion and culture may play a significant role in health-related issues. Healthcare workers should cooperate with patients to build strategies and plans that will improve patients' health-related quality of life (HRQoL), like minimising depression as their disease progresses. Emphasis on the need to help healthcare workers to concentrate on improving knowledge, understanding, motivation, experience, self-trust, and the formation of self-efficacy and self-management for patients receiving HD by designing interventions and empowerment programmes for this purpose.

\section{Methods}

\section{Purposes of the study}

The primary goals of this study were (1) to describe the relation between HD patients' self-efficacy and their QoL, (2) to assess factors associated with self-efficacy among HD patients, and (3) to assess factors associated with QoL among HD patients. The results of this study will be used to provide recommendations that may aid healthcare workers to teach patients the self-management-related skills for their chronic disease to help them become more confident in many aspects, such as solving their problems, performing activities and skills on their own, and overcoming barriers that affect their ideal disease selfmanagement in order to improve their QoL.

\section{Study design}

A cross-sectional study was conducted to achieve our objectives.

\section{Setting}

Patients included in the study were selected from every dialysis centre in the West Bank, Palestine. There are 12 dialysis centres in the West Bank: one is private (AnNajah University Hospital) and the others are governmental, including Al-Watani/Nablus, Tubas Turkish, Salfit (Yaser Arafat), Jenin (Khalil Souliman), Qalqiliya 
(Darweesh Nazal), Hebron (Alia), Tulkarm (Thabet Thabet), Jericho, Beit Jala (Al Housain), Palestine Medical Complex/Ramallah, and Yatta (Abu Al Hassan Al Kassem) [23].

\section{Study population}

There were 1014 dialysis patients who came regularly to the dialysis centres in the West Bank, according to the 2015 annual health report of the Palestinian Ministry of Health which was published at the time of the study [23]. In West Bank/ Palestine, there are 12 kidney dialysis units (11 units in hospitals of the Ministry of Health and one unit in An-Najah National University hospital in Nablus) with a total of 183 machines [22]. According to the 2017 annual health report of the Palestinian Ministry of Health, a total of 147,494 HD sessions took place in 2016 [22].

\section{Sampling procedure and sample size calculations}

To achieve the goal of this study, we used a web-based calculator, which is called the Raosoft sample size calculator, to determine the sample size [42]. We decided that the sample size will be 279 patients to get a 95\% confidence level and a 5\% margin of error, depending on the assumption that half of the patients correctly answered every question. The HD patients from this crosssectional study were chosen using a convenience sampling technique. HD patients were selected from all kidney dialysis units in West Bank/Palestine using the proportional quota sampling method to be representative of the general HD population (Table 1).

\section{Inclusion and exclusion criteria}

We included participants who met the following criteria: (1) patients older than 18 years of age, (2) confirmed diagnosis of ESRD, and (3) patients on regular HD therapy for at least 6 months. We excluded the patients who had major psychiatric disorders or were seriously ill at the time of the study. We also excluded patients if they were physically or mentally unable to communicate with the interviewer.

\section{Data collection instrument}

We used an instrument that contained four sections (see Additional file 1: English and Arabic version of the instrument):

The first section covered the social and demographic factors like age, sex, residency, occupational status, the dialysis centre visited, marital status, educational level, smoking status, and monthly income.

The second section discussed the clinical status of the patients, including questions such as how many hours per dialysis session, how many dialysis sessions per week, duration of disease in months, body mass index (BMI), how many medications they use regularly to calculate the total number of chronic medications, and how many chronic diseases they have to calculate the total number of co-morbid diseases. Therefore, the presence of one or more chronic diseases (co-morbidity) was calculated only for HD patients who had chronic diseases other than CKD. Furthermore, the total number of chronic medications used was defined as types of medication (i.e. prescriptions) used for certain chronic disease.

Table 1 Distribution of dialysis in hospitals, West Bank/Palestine, 2015 and 2016, and number of patients collected from each dialysis centre for the current study

\begin{tabular}{|c|c|c|c|c|}
\hline Hospital's name & $\begin{array}{l}\text { No. of patients in } \\
2015^{\mathrm{a}}\end{array}$ & $\begin{array}{l}\text { No. of patients collected for the current study } \\
\text { (\%) }\end{array}$ & $\begin{array}{l}\text { No. of patients in } \\
2016^{\mathrm{b}}\end{array}$ & $\begin{array}{l}\text { No. of } \\
\text { machines }\end{array}$ \\
\hline Jenin (Khalil Suliman) & 113 & $30(10.6)$ & 120 & 16 \\
\hline Tubas Turkish & 27 & $5(1.8)$ & 33 & 12 \\
\hline Tulkarm (Thabit Thabit) & 78 & $22(7.8)$ & 71 & 13 \\
\hline Al Watani $\backslash$ Nablus & 0 & $0(0.0)$ & 0 & 1 \\
\hline Qalqiliya (Darwish Nazal) & 47 & $13(4.6)$ & 51 & 12 \\
\hline Salfit (Yasser Arafat) & 32 & $9(3.2)$ & 34 & 9 \\
\hline Ramallah's Sons Ward & 137 & $45(15.9)$ & 157 & 21 \\
\hline Jericho & 25 & $8(2.8)$ & 29 & 9 \\
\hline Beit Jala (Al Housein) & 83 & $25(8.8)$ & 90 & 13 \\
\hline Hebron (Alia) & 220 & $62(21.9)$ & 245 & 32 \\
\hline $\begin{array}{l}\text { Yatta (Abu Alhasan Al } \\
\text { Kassem) }\end{array}$ & 42 & $10(3.5)$ & 52 & 10 \\
\hline An-Najah National University & 210 & $54(19.1)$ & 237 & 35 \\
\hline Total & 1014 & $283(100)$ & 1119 & 183 \\
\hline
\end{tabular}

${ }^{a}$ The data adapted from the 2016 annual health report of the Palestinian Ministry of Health [23]

${ }^{\mathrm{b}}$ The data adapted from the 2017 annual health report of the Palestinian Ministry of Health [22] 
The third part used the Self-Efficacy for Managing Chronic Disease Six-Item Scale (SEMCD-6), which is applied commonly in many chronic illnesses and concentrates on the level of confidence that the patients have in each area depending on a six-item scale. These areas include symptom control, emotional functioning, role function, and communication with doctors [43]. Relying on a 10-point rating scale, each question has a score varying from 1 to 10 ( 1 = totally not confident; 10 = very confident).

The fourth part used the Five-level EuroQol FiveDimensions (EQ-5D-5L) tool to assess the HRQoL. The Euro QoL Group developed this tool. It lets patients define their present health status during dialysis using a descriptive system of five items to measure the EQ-5D index score and the EQ visual analogue scale (EQ-VAS) [40]. We asked the patient to choose the most accurate sentence that describes his current health status, like the ability to walk: (1) I do not have any walking problems, (2) I have mild problems with walking, (3) I have moderate problems with walking, (4) I have severe problems with walking, and (5) I cannot walk. Permission to use the Arabic version of the EQ-5D [44] was offered by the Euro QOL Group, and it was scored according to Euro QOL guidelines [45]. The questionnaire was tested on a pilot sample of $15 \mathrm{HD}$ patients to evaluate comprehension. The pilot sample was not included in the final sample of the study. Face and content validity of the final data collection form was evaluated by a panel of three researchers who are experts in the field of QoL for assessing the preparation, organisation, translation, and evaluation. Some items were modified as necessary. Cronbach's alpha of the SEMCD-6 was 0.753, indicating acceptable internal consistency reliability. Additionally, Cronbach's alpha of five dimensions of the EQ-5D index was 0.771 , indicating acceptable internal consistency reliability.

\section{Ethical approval}

Ethical approval for the study was obtained from the local health authorities that had control and rule over the local study population and from An-Najah National University's Ethics Committee. We described the interview content to the respondents, and before the start of the interview, we obtained verbal consent from each participant.

\section{Statistical analysis}

Data analysis was performed using the Statistical Package for Social Sciences programme, version 15 (SPSS). Data for categorical variables were presented as frequencies (percentages), and data for continuous variables were presented as mean $\pm \mathrm{SD}$ or as medians (lowerupper quartiles). We utilised the Kolmogorov-Smirnov test to assess variables for normality use. The KruskalWallis test and Mann-Whitney test were used to test for differences in the medians between groups. Correlation between SEMCD-6 and HRQoL scale scores was investigated using Spearman's correlation coefficient. Linear regression analysis was carried out to assess the association of factors with each of the SEMCD-6 and HRQoL scale scores. The significance level was set at a $p$ value $<0.05$. Internal consistency reliability for all scales was calculated using Cronbach's alpha.

\section{Results}

\section{Participants' characteristics}

A total of 301 individuals were interviewed within 7 months from November 2016 to June 2017. Eighteen patients refused to participate, giving a response rate of 94\%. After excluding non-responses, the final sample was 283 . The majority of patients were aged between 30 and 60 years $(61.1 \%)$, and the patients' mean age was 50 . $3 \pm 16$ years. Most participants were male (61.8\%), married $(74.2 \%)$, unemployed $(79.9 \%)$, and living with their families (94.3\%). Nearly half (44.5\%) of the patients were categorised with a higher educational level (i.e. university level and above) and with less than 2000 New Israeli Shekel (NIS) monthly income (50.9\%) (Table 2).

In terms of their medical aspect, the length of dialysis ranged from 6 months to 252 months, with the majority at less than 48 months (72.4\%) and three dialysis sessions weekly (88\%). Regarding the dialysis sessions' duration, about half of the patients took more than 3 hours (51.6\%). Eighty-seven percent of patients did not have a kidney transplant history. Most had at least one chronic co-morbid disease $(83.3 \%)$ and were on regular medications (78.4\%) (Table 2).

\section{Self-efficacy scale}

The mean and median of the SEMCD- 6 were $38.70 \pm 11$. 1 and 39 (interquartile range: 31-47), respectively. Table 3 presents the factors associated with the SEMCD score. We found a significant association between age and SEMCD score $(p$ value $<0.05)$, where younger ages had better scores. There was also a significantly better SEMCD score with graduated patients than more uneducated ones, and the same for those who live alone, patients with high income, and employed patients. Other sociodemographic factors, such as BMI, residency, marital status, and smokers, were not significantly associated with SEMCD score ( $p$ value $>0.05)$.

Patients without any co-morbid conditions or low rates of co-morbid conditions in patients with HD and a low number of chronic medications were significantly associated with a high SEMCD score ( $p$ value <0.05). Other clinical factors such as dialysis vintage, dialysis per week, dialysis duration, and history of kidney 
Table 2 Sociodemographic and clinical characteristics of participants

\begin{tabular}{|c|c|}
\hline Variable & Frequency (\%) N (283) \\
\hline \multicolumn{2}{|l|}{ Age category (years) } \\
\hline$<30$ & $36(12.7)$ \\
\hline $30-60$ & $173(61.1)$ \\
\hline$>60$ & $74(26.1)$ \\
\hline \multicolumn{2}{|l|}{ Gender } \\
\hline Male & 175(61.8) \\
\hline Female & 108(38.2) \\
\hline \multicolumn{2}{|l|}{$B M l^{\mathrm{a}}$} \\
\hline Underweight & $16(5.7)$ \\
\hline Normal & 107(37.8) \\
\hline Overweight & $92(32.5)$ \\
\hline Obese & $68(24)$ \\
\hline \multicolumn{2}{|l|}{ Education } \\
\hline No formal education & $20(7.1)$ \\
\hline Elementary school (primary) & $63(22.3)$ \\
\hline High school (secondary school) & $74(26.1)$ \\
\hline Graduated (university and above) & $126(44.5)$ \\
\hline \multicolumn{2}{|l|}{ Household income (month) ${ }^{a}$} \\
\hline High (more than 5000 NIS) & $16(5.7)$ \\
\hline Moderate (2000-5000 NIS) & $123(43.5)$ \\
\hline Low (less than 2000 NIS) & 144(50.9) \\
\hline \multicolumn{2}{|l|}{ Residency } \\
\hline City and refugee camps & 115(40.6) \\
\hline Village & 168(59.4) \\
\hline \multicolumn{2}{|l|}{ Living status } \\
\hline Alone & $16(5.7)$ \\
\hline With family & 267(94.3) \\
\hline \multicolumn{2}{|l|}{ Marital status } \\
\hline Single, divorced, widowed & $73(25.8)$ \\
\hline Married & 210(74.2) \\
\hline \multicolumn{2}{|l|}{ Occupation } \\
\hline Employed & $57(20.1)$ \\
\hline Unemployed & 226(79.9) \\
\hline \multicolumn{2}{|l|}{ Dialysis vintage (months) } \\
\hline$<48$ & $205(72.4)$ \\
\hline$\geq 48$ & $78(27.6)$ \\
\hline \multicolumn{2}{|l|}{ Dialysis per week } \\
\hline$\leq 2$ & $29(10.2)$ \\
\hline 3 & 249(88.0) \\
\hline$\geq 4$ & $5(1.8)$ \\
\hline \multicolumn{2}{|l|}{ Dialysis session duration (hours) } \\
\hline$\leq 3$ & 137(48.4) \\
\hline$>3$ & $146(51.6)$ \\
\hline
\end{tabular}

Table 2 Sociodemographic and clinical characteristics of participants (Continued)

\begin{tabular}{lc}
\hline Variable & Frequency (\%) N (283) \\
\hline $\begin{array}{l}\text { Transplantation history } \\
\text { Yes }\end{array}$ & $35(12.4)$ \\
No & $248(87.6)$ \\
Total chronic co-morbid diseases & \\
None & $47(16.6)$ \\
1 & $74(26.1)$ \\
2 & $68(24.0)$ \\
$\geq 3$ & $94(33.2)$ \\
Chronic medications & \\
$<4$ & $61(21.6)$ \\
$\geq 4$ & $222(75.4)$ \\
\hline $\begin{array}{l}\text { Abbreviations: BMI body mass index, NIS New Israeli Shekel } \\
\text { a1 Israeli New Shekel equals } 0.29 \text { US Dollar }\end{array}$
\end{tabular}

transplant were not significantly associated with SEMCD score ( $p$ value $>0.05)$.

\section{EQ-5D index values and EQ-VAS score}

The mean and median of the EQ-5D index value were 0 . $46 \pm 0.35$ and 0.53 (interquartile range, 0.22-0.74), respectively. The mean and median of the EQ-VAS were $65.5 \pm 21.9$ and 70 (interquartile range, 50-80), respectively. Table 4 presents the factors associated with EQ-5D score. We found that factors such as age, education level, income, living status, occupation, dialysis session duration, transplantation history, total number of comorbid diseases, and number of medications were significantly associated with EQ-5D score $(p$ value $<0.05)$. Correlation tests revealed moderately positive association between the EQ-5D score and the EQ-VAS $(r=0$. $486, p$ value $<0.001)$ and SEMCD-6 $(r=0.497, p$ value $<$ $0.001)$.

\section{Multiple linear regression analysis}

The multiple linear regression model of the SEMCD-6 scale is shown in Table 5. Age, education level, income, living status, occupation, total number of co-morbid diseases, and number of medications were included as independent variables. Table 5 shows that age, living status, and number of co-morbid diseases were negatively associated with SEMCD-6 score $(\beta=-2.66, p=0$. 016; $\beta=-5.71, p=0.033 ; \beta=-1.84, p=0.006$, respectively). More specifically, being younger, living alone, and having a low number of co-morbid diseases were associated with a higher SEMCD-6 score.

The multiple linear regression model of the HRQoL scale is shown in Table 6. Age, education level, income, living status, occupation, dialysis session duration, transplantation history, total number of co-morbid diseases, 
Table 3 Association of sociodemographic and clinical characteristics with self-efficacy score in haemodialysis patients with chronic kidney disease

\begin{tabular}{|c|c|c|c|}
\hline Variable & Frequency (\%) $N(283)$ & Median (Q1-Q3) & $P$ value $^{a}$ \\
\hline \multicolumn{4}{|l|}{ Age category (years) } \\
\hline$<30$ & $36(12.7)$ & $46(36-52.75)$ & \multirow[t]{3}{*}{$<0.001^{b}$} \\
\hline $30-60$ & 173(61.1) & $40(33-47.5)$ & \\
\hline$>60$ & $74(26.1)$ & $33(26-41.25)$ & \\
\hline \multicolumn{4}{|l|}{ Gender } \\
\hline Male & 175(61.8) & $38(32-47)$ & \multirow[t]{2}{*}{$0.958^{c}$} \\
\hline Female & 108(38.2) & $40(31-48.75)$ & \\
\hline \multicolumn{4}{|l|}{$B M l^{\mathrm{a}}$} \\
\hline Underweight & $16(5.7)$ & $37(31-48.5)$ & \multirow[t]{4}{*}{$0.206^{\mathrm{b}}$} \\
\hline Normal & 107(37.8) & $41(33-50)$ & \\
\hline Overweight & $92(32.5)$ & $39(29-46)$ & \\
\hline Obese & $68(24)$ & $37(31-45)$ & \\
\hline \multicolumn{4}{|l|}{ Education } \\
\hline No formal education & $20(7.1)$ & $34.5(28-48)$ & \multirow[t]{4}{*}{$0.014^{b}$} \\
\hline Elementary school (primary) & $63(22.3)$ & $35(27-43)$ & \\
\hline High school (secondary school) & $74(26.1)$ & $39.5(31-49)$ & \\
\hline Graduated (university and above) & $126(44.5)$ & $41(34-48.25)$ & \\
\hline \multicolumn{4}{|l|}{ Household income (month) ${ }^{d}$} \\
\hline High (more than $5000 \mathrm{NIS}$ ) & $16(5.7)$ & $43(34-50.5)$ & \multirow[t]{3}{*}{$0.005^{\mathrm{b}}$} \\
\hline Moderate (2000-5000 NIS) & $123(43.5)$ & $42(34-49)$ & \\
\hline Low (less than 2000 NIS) & 144(50.9) & $37(29.25-45)$ & \\
\hline \multicolumn{4}{|l|}{ Residency } \\
\hline City and refugee camps & 115(40.6) & $39(31-47)$ & \multirow[t]{2}{*}{$0.995^{c}$} \\
\hline Village & 168(59.4) & $39(31-47.75)$ & \\
\hline \multicolumn{4}{|l|}{ Living status } \\
\hline Alone & $16(5.7)$ & $45(38-54.25)$ & \multirow[t]{2}{*}{$0.031^{c}$} \\
\hline With family & 267(94.3) & $39(31-47)$ & \\
\hline \multicolumn{4}{|l|}{ Marital status } \\
\hline Single, divorced, widowed & $73(25.8)$ & $40(31.5-49)$ & \multirow[t]{2}{*}{$0.438^{c}$} \\
\hline Married & $210(74.2)$ & $38.5(31-47)$ & \\
\hline \multicolumn{4}{|l|}{ Occupation } \\
\hline Employed & $57(20.1)$ & $45(37-50)$ & \multirow[t]{2}{*}{$<0.001^{c}$} \\
\hline Unemployed & 226(79.9) & $38(30-46)$ & \\
\hline \multicolumn{4}{|l|}{ Dialysis vintage (months) } \\
\hline$<48$ & 205(72.4) & $39(31-47)$ & \multirow[t]{2}{*}{$0.905^{c}$} \\
\hline$\geq 48$ & $78(27.6)$ & $38.5(32.75-47)$ & \\
\hline \multicolumn{4}{|l|}{ Dialysis per week } \\
\hline$\leq 2$ & $29(10.2)$ & $40(27.5-48.5)$ & \multirow[t]{3}{*}{$0.908^{b}$} \\
\hline 3 & 249(88.0) & $39(31-47)$ & \\
\hline$\geq 4$ & $5(1.8)$ & $37(19-48)$ & \\
\hline \multicolumn{4}{|l|}{ Dialysis session duration (hours) } \\
\hline$\leq 3$ & 137(48.4) & $38(32-46)$ & \multirow[t]{2}{*}{$0.482^{c}$} \\
\hline$>3$ & $146(51.6)$ & $40(30-48.25)$ & \\
\hline
\end{tabular}


Table 3 Association of sociodemographic and clinical characteristics with self-efficacy score in haemodialysis patients with chronic kidney disease (Continued)

\begin{tabular}{lll}
\hline Variable & Frequency (\%) N(283) & Median (Q1-Q3) \\
\hline $\begin{array}{l}\text { Transplantation history } \\
\text { Yes }\end{array}$ & $35(12.4)$ & $39(34-52)$ \\
No & $248(87.6)$ & $39(31-47)$ \\
Total chronic co-morbid diseases & & \\
None & $47(16.6)$ & $44(37-51)$ \\
1 & $74(26.1)$ & $42(33.75-50)$ \\
2 & $68(24.0)$ & $39.5(31-48.75)$ \\
$\geq 3$ & $94(33.2)$ & $35(28-41)$ \\
Chronic medications & & \\
$<4$ & $61(21.6)$ & $42(34-51)$ \\
$\geq 4$ & $222(75.4)$ & $38(30-46)$ \\
\hline Abbra
\end{tabular}

Abbreviations: $B M I$ body mass index, NIS New Israeli Shekel

${ }^{\text {aThe }} p$ values are italicized where they are less than the significance level cut-off of 0.05

${ }^{\mathrm{b}}$ Statistical significance of differences calculated using the Kruskal-Wallis test

cStatistical significance of differences calculated using the Mann-Whitney $U$ test

$\mathrm{d}_{1}$ Israeli New Shekel equals 0.29 US Dollar

number of medications, and SEMCD-6 score were included as independent variables once interactions such as EQ-VAS were excluded. As shown in Table 6, there is a positive association between the educational level and the SEMCD-6 score with the QoL score $(\beta=0.05, p=0$. 017; $\beta=0.01, p<0.001$, respectively), while there is a negative association between the number of co-morbid diseases and the QoL score $(\beta=-0.07, p=0.001)$. More specifically, patients with a high education level, greater levels of self-efficacy, and a low number of co-morbid diseases were associated with a higher QoL score.

\section{Discussion}

In the current study, we examined HD patients on different levels demographically and clinically using SEMCD-6 scores, EQ5D scores, and EQ-VAS scores. We found a significant relation between SEMCD-6 score and age, education status, monthly household income, living status, occupation, total chronic co-morbid diseases, and regular medications. There was a significant relation between age, monthly household income, occupation, total chronic co-morbid diseases, and regular medications and EQ-VAS score. Moreover, a significant relation was found between age, education status, monthly household income, living status, occupation, current smoking status, dialysis session duration, transplantation history, total chronic co-morbid diseases, and chronic medications and EQ-5D score.

In the current study, the mean of SEMCD-6 was 38 . $70, \mathrm{SD}=11.06$. Surprisingly, the mean score was found to be a little bit lower in comparison to that in a previous American study's mean and SD = 48.66 (10.79) [11]. The results of our study showed that a younger age is significantly associated with better self-efficacy. This finding supports previous research in this area that links age and self-efficacy [11]. It is important to note that the mean age of participants for the American study's was 50.9 years [11] which is considered close to the mean age in our sample.

Employed patients with a higher monthly income are strongly associated with a better self-efficacy score. This result is in accordance with a previous Turkish study [26] and Callaghan's study [46]. In the current study, we found that patients with more education have a better SEMCD-6 score. This result is in agreement with results obtained by Curtin et al. [11]. It is also consistent with Kav et al.'s research, which studied the self-efficacy of diabetic patients [47].

We obtained from our results a significant relation between living status and SEMCD-6 score. People who live alone have better self-efficacy than those who live with their families. This result seems to be consistent with another Turkish study, which found the same result in diabetic patients [47]. It is interesting to note that in this study, self-efficacy was inversely associated with the number of co-morbid diseases and medications. Patients who have no or fewer medications or co-morbid diseases have better self-efficacy. However, this result has not previously been described. This is an important issue for future research.

In our study, the EQ-5D score showed a mean of 0.46 $(\mathrm{SD}=0.35)$, which is lower than other studies' means, such as a Swiss study that had a mean of $0.62(\mathrm{SD}=0$. 30) [48], an English and Welsh study with a mean of 0. $60(\mathrm{SD}=0.28)$ [49], and a Japanese study with a mean of $0.75(\mathrm{SD}=0.17)$ [50]. 
Table 4 Association of sociodemographic and clinical characteristics with health-related quality of life in haemodialysis patients with chronic kidney disease

\begin{tabular}{|c|c|c|c|}
\hline Variable & Frequency (\%) N (283) & Median (Q1-Q2) & $P$ value \\
\hline \multicolumn{4}{|l|}{ Age category (years) } \\
\hline$<30$ & $36(12.7)$ & $0.74(0.43-0.84)$ & \multirow[t]{3}{*}{$<0.001^{b}$} \\
\hline $30-60$ & 173(61.1) & $0.55(0.25-0.74)$ & \\
\hline$>60$ & $74(26.1)$ & $0.31(0.06-0.59)$ & \\
\hline \multicolumn{4}{|l|}{ Gender } \\
\hline Male & 175(61.8) & $0.52(0.19-0.73)$ & \multirow[t]{2}{*}{$0.965^{c}$} \\
\hline Female & 108(38.2) & $0.55(0.25-0.74)$ & \\
\hline \multicolumn{4}{|l|}{$B M l^{\mathrm{a}}$} \\
\hline Underweight & $16(5.7)$ & $0.33(-0.03-0.76)$ & \multirow[t]{4}{*}{$0.070^{\mathrm{b}}$} \\
\hline Normal & 107(37.8) & $0.59(0.26-0.78)$ & \\
\hline Overweight & $92(32.5)$ & $0.54(0.29-0.73)$ & \\
\hline Obese & $68(24)$ & $0.41(0.12-0.70)$ & \\
\hline \multicolumn{4}{|l|}{ Education } \\
\hline No formal education & $20(7.1)$ & $0.28(-0.05-0.63)$ & \multirow[t]{4}{*}{$<0.001^{b}$} \\
\hline Elementary school (primary) & $63(22.3)$ & $0.36(0.08-0.62)$ & \\
\hline High school (secondary school) & $74(26.1)$ & $0.48(0.16-0.74)$ & \\
\hline Graduated (university and above) & $126(44.5)$ & $0.67(0.39-0.80)$ & \\
\hline \multicolumn{4}{|l|}{ Household income (month) ${ }^{d}$} \\
\hline High (more than 5000 NIS) & $16(5.7)$ & $0.67(0.56-0.87)$ & \multirow[t]{3}{*}{$0.001^{\mathrm{b}}$} \\
\hline Moderate (2000-5000 NIS) & $123(43.5)$ & $0.66(0.29-0.77)$ & \\
\hline Low (less than 2000 NIS) & 144(50.9) & $0.44(0.13-0.68)$ & \\
\hline \multicolumn{4}{|l|}{ Residency } \\
\hline City and refugee camps & 115(40.6) & $0.55(0.21-0.77)$ & \multirow[t]{2}{*}{$0.566^{c}$} \\
\hline Village & 168(59.4) & $0.52(0.22-0.71)$ & \\
\hline \multicolumn{4}{|l|}{ Living status } \\
\hline Alone & $16(5.7)$ & $0.73(0.53-0.87)$ & \multirow[t]{2}{*}{$0.00 x^{c}$} \\
\hline With family & 267(94.3) & $0.50(0.19-0.73)$ & \\
\hline \multicolumn{4}{|l|}{ Marital status } \\
\hline Single, divorced, widowed & $73(25.8)$ & $0.60(0.25-0.74)$ & \multirow[t]{2}{*}{$0.453^{c}$} \\
\hline Married & 210(74.2) & $0.50(0.19-0.74)$ & \\
\hline \multicolumn{4}{|l|}{ Occupation } \\
\hline Employed & $57(20.1)$ & $0.71(0.50-0.80)$ & \multirow[t]{2}{*}{$<0.001^{c}$} \\
\hline Unemployed & 226(79.9) & $0.45(0.17-0.71)$ & \\
\hline \multicolumn{4}{|l|}{ Dialysis vintage (months) } \\
\hline$<48$ & 205(72.4) & $0.53(0.20-0.74)$ & \multirow[t]{2}{*}{$0.741^{\mathrm{C}}$} \\
\hline$\geq 48$ & $78(27.6)$ & $0.48(0.28-0.73)$ & \\
\hline \multicolumn{4}{|l|}{ Dialysis per week } \\
\hline$\leq 2$ & $29(10.2)$ & $0.40(0.06-0.74)$ & \multirow[t]{3}{*}{$0.391^{b}$} \\
\hline 3 & 249(88.0) & $0.54(0.24-0.74)$ & \\
\hline$\geq 4$ & $5(1.8)$ & $0.43(0.01-0.73)$ & \\
\hline \multicolumn{4}{|l|}{ Dialysis session duration (hours) } \\
\hline$\leq 3$ & 137(48.4) & $0.45(0.15-0.69)$ & \multirow[t]{2}{*}{$0.012^{c}$} \\
\hline$>3$ & $146(51.6)$ & $0.61(0.27-0.77)$ & \\
\hline
\end{tabular}


Table 4 Association of sociodemographic and clinical characteristics with health-related quality of life in haemodialysis patients with chronic kidney disease (Continued)

\begin{tabular}{|c|c|c|c|}
\hline Variable & Frequency (\%) N (283) & Median (Q1-Q2) & $P$ value $^{a}$ \\
\hline \multicolumn{4}{|c|}{ Transplantation history } \\
\hline Yes & $35(12.4)$ & $0.71(0.48-0.80)$ & \multirow[t]{2}{*}{$0.001^{c}$} \\
\hline No & 248(87.6) & 0.48(0.19-0.71) & \\
\hline \multicolumn{4}{|c|}{ Total chronic co-morbid diseases } \\
\hline None & $47(16.6)$ & $0.71(0.53-0.84)$ & \multirow[t]{4}{*}{$<0.001^{b}$} \\
\hline 1 & $74(26.1)$ & $0.69(0.34-0.84)$ & \\
\hline 2 & $68(24.0)$ & $0.45(0.21-0.70)$ & \\
\hline$\geq 3$ & $94(33.2)$ & $0.29(0.06-0.55)$ & \\
\hline \multicolumn{4}{|c|}{ Chronic medications } \\
\hline$<4$ & $61(21.6)$ & $0.70(0.29-0.78)$ & \multirow[t]{2}{*}{$0.00 x^{c}$} \\
\hline$\geq 4$ & $222(75.4)$ & $0.48(0.19-0.71)$ & \\
\hline
\end{tabular}

Abbreviations: BMI body mass index, NIS New Israeli Shekel

aThe $p$ values are italicized where they are less than the significance level cut-off of 0.05

${ }^{\mathrm{b}}$ Statistical significance of differences calculated using the Kruskal-Wallis test

'Statistical significance of differences calculated using the Mann-Whitney $U$ test

$\mathrm{d}_{1}$ Israeli New Shekel equals 0.29 US Dollar

In the present study, we found a significant association between higher QoL and younger age. This finding is in agreement with that obtained by an Iranian study [51]. This contrasts with the study of O'Reilly et al., which explained that HRQoL gets better when the patient is older in age [52]. A higher education level was associated with better QoL. This result is consistent with data obtained in a previous Iranian study [51]. A study in the United Arab Emirates, which used another score for QoL measurement, matches our result [53]. Our study revealed that the total number of co-morbid diseases was inversely associated with QoL. This finding is in agreement with two Iranian studies that showed a strong relation between the number of co-morbid diseases and poor QoL [54, 55].

One interesting finding associated with the dialysis session duration is that QoL is better with longer session duration. Dialysis adequacy may be the answer because shorter dialysis session may result in inadequate dialysis [56]. This suggestion reflects those of Adas et al. [35] who also found that most patients in Palestine were inadequately dialyzed and a high percentage of the HD patients did not achieve the targets. This result seems to be consistent with other research, which found that initiating HD at longer session duration is associated with less mortality [57]. This result is also in agreement with results obtained by a Belgian study that found a longer duration improves the well-being of patients due to more removal of solutes from patients in the interdialytic period [58]. In our data, high income was associated with better QoL, which supports a previous Iranian study by Pakpour et al. [54]. Another study was conducted by Marinovich et al. [59], which further supports the association between high income and better QoL.

Another important finding was that patients who have undergone kidney transplantation have higher QoL. This result is in accordance with a recent study by Fiebiger et al. [60]. This corroborate the ideas of Laupacis et al. [61], who suggested that renal transplantation improves the HRQoL of patients on dialysis.

Table 5 Patients characteristics associated with self-efficacy in multiple linear regression

\begin{tabular}{|c|c|c|c|c|c|}
\hline Variables $^{a}$ & Unstandardised coefficients ( $\beta$ ) & S.E & Standardised coefficients $(\beta)$ & $P$ value ${ }^{b}$ & 95\% confidence interval for $\beta$ \\
\hline Age & -2.66 & 1.10 & -0.15 & 0.016 & -4.83 to -0.50 \\
\hline Education level & 0.49 & 0.69 & 0.04 & 0.482 & -0.87 to 1.84 \\
\hline Income & 1.91 & 1.14 & 0.10 & 0.095 & -0.34 to 4.15 \\
\hline Living status & -5.71 & 2.66 & -0.12 & 0.033 & -10.95 to -0.48 \\
\hline Occupation & 3.04 & 1.67 & 0.11 & 0.070 & -0.25 to 6.33 \\
\hline Number of co-morbid diseases & -1.84 & 0.66 & -0.18 & 0.006 & -3.15 to -0.54 \\
\hline Number of chronic medications & -1.75 & 1.65 & -0.07 & 0.290 & -5.01 to 1.50 \\
\hline
\end{tabular}

anivariate factors with $p$ values $<0.05$ were entered into the multiple linear regression

${ }^{\mathrm{b}}$ The $p$ values are italicized where they are less than the significance level cut-off of 0.05 
Table 6 Patients characteristics associated with quality of life in multiple linear regression

\begin{tabular}{|c|c|c|c|c|c|}
\hline Variables ${ }^{a}$ & $\begin{array}{l}\text { Unstandardised coefficients } \\
(\beta)\end{array}$ & S.E & $\begin{array}{l}\text { Standardised coefficients } \\
\text { ( } \beta \text { ) }\end{array}$ & $\begin{array}{l}P \text { value } \\
b\end{array}$ & $\begin{array}{l}95 \% \text { confidence interval for } \\
\beta\end{array}$ \\
\hline Age & -0.03 & 0.03 & -0.05 & 0.402 & -0.09 to 0.04 \\
\hline Education level & 0.05 & 0.02 & 0.13 & 0.017 & 0.01 to 0.09 \\
\hline Income & 0.04 & 0.03 & 0.06 & 0.257 & -0.03 to 0.10 \\
\hline Living status & -0.15 & 0.08 & -0.09 & 0.062 & -0.30 to 0.01 \\
\hline Occupation & 0.04 & 0.05 & 0.04 & 0.449 & -0.06 to 0.13 \\
\hline Dialysis session duration (hours) & 0.03 & 0.04 & 0.05 & 0.356 & -0.04 to 0.11 \\
\hline Transplantation history & -0.04 & 0.06 & -0.04 & 0.495 & -0.15 to 0.07 \\
\hline Number of co-morbid diseases & -0.07 & 0.02 & -0.21 & 0.001 & -0.11 to -0.03 \\
\hline Number of chronic medications & 0.03 & 0.05 & 0.04 & 0.512 & -0.06 to 0.13 \\
\hline $\begin{array}{l}\text { Self-Efficacy for Managing Chronic Disease } \\
\text { score }\end{array}$ & 0.01 & 0.00 & 0.37 & $<0.001$ & 0.01 to 0.02 \\
\hline
\end{tabular}

score

anivariate factors with $p$ values $<0.05$ were entered into the multiple linear regression

${ }^{\mathrm{b}}$ The $p$ values are bold where they are less than the significance level cut-off of 0.05

The most important finding in our study was the significant relation between self-efficacy and QoL. Patients with a higher self-efficacy score had better QoL. This result is in accordance with a previous Taiwanese study by Tsay and Healstead [4]. It is also in agreement with Lev and Owen's research [62], which showed that QoL is positively related to self-efficacy.

\section{Strength and limitations}

The key strengths of this study are the collection of data from all dialysis centres in the West Bank, which means a relatively large sample, as well as the performance of direct interviews with the patients to collect more realistic and valid information. However, no studies have been performed to calculate the self-efficacy and QoL of HD patients in Palestine. This is the first study to evaluate the association between SEMCD-6 and QoL among HD patients in Palestine.

The study is limited by a number of restrictions that should be discussed. The first limitation is that the generalisability of the study's results to other CKD patients is reduced, because we used a convenience sampling method. The second limitation is that the crosssectional design precludes any statements about causal associations between study variables. The third limitation is that related to selection bias that may have been introduced into the sample due to the non-response rate among eligible participants, inclusion or exclusion patients according to eligible criteria, or due to the nonrandom selection of initial participants. Additionally, our result may be confounded by survivor bias, e.g. those patients who live alone with a poor SEMCD score may die very quickly without help from their family and some degree of survivor bias cannot be excluded.

\section{Conclusions}

This study assessed factors associated with impaired self-efficacy and HRQoL in HD patients. The results of this investigation show that impaired self-efficacy was associated with the elderly, patients living with family, and patients with a high number of co-morbid diseases. Furthermore, this study found that the worst HRQoL was associated with patients with low education level, lower levels of self-efficacy, and a high number of comorbid diseases. The results of this investigation show that assessment of the self-efficacy of patients receiving HD is crucial in clinical practice. Doctors may require self-efficacy trainings to strengthen HD patients' trust in carrying out self-care behaviours, which can lead to improvement in their QoL. Future studies that examine the effect of dialysis adequacy by calculating the $\mathrm{Kt} / \mathrm{V}$ or urea reduction ratio on QoL in HD patients are needed.

\section{Additional file}

Additional file 1: Study questionnaires. This is the final version of the English and Arabic version that was used to obtain data which will help to address the factors associated with self-efficacy and health-related quality of life (HRQOL) among haemodialysis (HD) patients in Palestine. (DOCX 366 kb)

\section{Abbreviations}

BMI: Body mass index; DM: Diabetes mellitus; EQ-5D-5L: Five-Level EuroQol Five-Dimensions; EQ-VAS: EuroQol visual analogue scale; ESRD: End-stage renal disease; HRQOL: Health-related quality of life; NIS: New Israeli Shekel; SD: Standard deviation; SEMCD-6: Self-Efficacy for Managing Chronic Disease Six-Item Scale; US\$: The United States dollar

\section{Acknowledgements}

The authors would like to thank An-Najah National University for providing the opportunity to conduct this study.

Availability of data and materials

The datasets used and/or analysed during the current study are available from the corresponding author on reasonable request. 


\section{Authors' contributions}

IM, RA, and KA collected data, performed the analyses, searched the literature, and drafted the manuscript. AA participated in the field study and in the development of the final version of the manuscript. SZ conceptualised and designed the study; coordinated, supervised, and analysed the data; critically reviewed the manuscript and the interpretation of the results; and assisted in the final write-up of the manuscript and the revised manuscript. All authors read and approved the final manuscript.

\section{Ethics approval and consent to participate}

Ethical approval was obtained for the study from the local health authorities that had control and rule over the local study population and from An-Najah National University's Ethics Committee. We described the interview content to the respondents, and before the start of the interview, we obtained verbal consent from each participant.

\section{Competing interests}

The authors declare that they have no competing interests.

\section{Publisher's Note}

Springer Nature remains neutral with regard to jurisdictional claims in published maps and institutional affiliations.

\section{Author details}

'Department of Medicine, College of Medicine and Health Sciences, An-Najah National University, Nablus 44839, Palestine. ${ }^{2}$ Public Health Department, College of Medicine and Health Sciences, An-Najah National University Hospital, An-Najah National University, Nablus 44839, Palestine. ${ }^{3}$ Poison Control and Drug Information Center (PCDIC), College of Medicine and Health Sciences, An-Najah National University, Nablus 44839, Palestine. ${ }^{4}$ Department of Clinical and Community Pharmacy, College of Medicine and Health Sciences, An-Najah National University, Nablus 44839, Palestine. ${ }^{5}$ Division of Clinical and Community Pharmacy, Department of Pharmacy, College of Medicine and Health Sciences, An-Najah National University, Nablus 44839, Palestine.

\section{Received: 23 January 2018 Accepted: 16 April 2018 Published online: 09 May 2018}

\section{References}

1. Bruck K, Jager KJ, Dounousi E, Kainz A, Nitsch D, Arnlov J, Rothenbacher D, Browne G, Capuano V, Ferraro PM, et al. Methodology used in studies reporting chronic kidney disease prevalence: a systematic literature review. Nephrol Dial Transplant. 2015;30(Suppl 4):iv6-16.

2. Khader MI, Snouber S, Alkhatib A, Nazzal Z, Dudin A. Prevalence of patients with end-stage renal disease on dialysis in the West Bank, Palestine. Saudi J Kidney Dis Transpl. 2013;24:832-7.

3. Lin CC, Wu CC, Anderson RM, Chang CS, Chang SC, Hwang SJ, Chen HC The chronic kidney disease self-efficacy (CKD-SE) instrument: development and psychometric evaluation. Nephrol Dial Transplant. 2012;27:3828-34.

4. Tsay SL, Healstead M. Self-care self-efficacy, depression, and quality of life among patients receiving hemodialysis in Taiwan. Int J Nurs Stud. 2002;39:245-51.

5. Coentrao L, Van Biesen W, Nistor I, Tordoir J, Gallieni M, Marti Monros A, Bolignano D. Preferred haemodialysis vascular access for diabetic chronic kidney disease patients: a systematic literature review. J Vasc Access. 2015; 16:259-64.

6. Caramori ML, Mauer M. Diabetes and nephropathy. Curr Opin Nephrol Hypertens. 2003;12:273-82.

7. Lim A. Diabetic nephropathy—complications and treatment. Int J Nephrol Renovasc Dis. 2014;7:361-81.

8. Dabla PK. Renal function in diabetic nephropathy. World J Diabetes. 2010;1:48-56

9. Johnson ML, Zimmerman L, Welch JL, Hertzog M, Pozehl B, Plumb T. Patient activation with knowledge, self-management and confidence in chronic kidney disease. J Ren Care. 2016;42:15-22.

10. Oller GA, Ribeiro Rde C, Travagim DS, Batista MA, Marques S, Kusumota L. Functional independence in patients with chronic kidney disease being treated with haemodialysis. Rev Lat Am Enfermagem. 2012;20:1033-40.

11. Curtin RB, Walters BA, Schatell D, Pennell P, Wise M, Klicko K. Self-efficacy and self-management behaviors in patients with chronic kidney disease. Adv Chronic Kidney Dis. 2008;15:191-205.
12. Zrinyi M, Juhasz M, Balla J, Katona E, Ben T, Kakuk G, Pall D. Dietary selfefficacy: determinant of compliance behaviours and biochemical outcomes in haemodialysis patients. Nephrol Dial Transplant. 2003;18:1869-73.

13. Tsay SL. Self-efficacy training for patients with end-stage renal disease. J Adv Nurs. 2003;43:370-5.

14. Lindberg M, Fernandes MA. Self-efficacy in relation to limited fluid intake amongst Portuguese haemodialysis patients. J Ren Care. 2010;36:133-8.

15. Winters AM, Lindberg M, Sol BG. Validation of a Dutch self-efficacy scale for adherence to fluid allowance among patients on haemodialysis. J Ren Care. 2013;39:31-8

16. Oka M, Chaboyer W. Influence of self-efficacy and other factors on dietary behaviours in Japanese haemodialysis patients. Int J Nurs Pract. 2001;7:431-9.

17. Balaga PAG. Self-efficacy and self-care management outcome of chronic renal failure patients. Asian J Health. 2012;2:111-29.

18. Lin CC, Tsai FM, Lin HS, Hwang SJ, Chen HC. Effects of a self-management program on patients with early-stage chronic kidney disease: a pilot study. Appl Nurs Res. 2013;26:151-6.

19. Moattari M, Ebrahimi M, Sharifi N, Rouzbeh J. The effect of empowerment on the self-efficacy, quality of life and clinical and laboratory indicators of patients treated with hemodialysis: a randomized controlled trial. Health Qual Life Outcomes. 2012:10:115.

20. Barata NE. Dyadic relationship and quality of life patients with chronic kidney disease. J Bras Nefrol. 2015;37:315-22.

21. Mosleh M, Dalal K, Aljeesh Y. Burden of chronic diseases in the Palestinian health-care sector using disability-adjusted life-years. Lancet. 2018;391:S21.

22. Ministry of Health, Palestinian Health Information Center. Health Annual Report, Palestine 2016. 2017 [cited 2018 January 20]; Available from: http://www.moh.ps/Content/Books/ZxRcynmiUofNat66u4CrHRgm JR6Uv7z77srjj|EAho6xnz5V3rgLTu_RhO7xf2j2VusNilvWkjwp84yXHLdGleB 97gKrHHI5iZ9oPJ25owGEN.pdf.

23. Ministry of Health, Palestinian Health Information Center. Health Status, Palestine, 2015. 2016 [cited 2017 February 17]; Available from: http://www. moh.ps/Content/Books/ NWNJXX7RJ92Bn4f5EGYiH43a2tjAAzKBnseGnEUCaqWqYZndsbCcPy_ JQWguvkHTR4Xk4zUpdT450oWxH11BhlbVAxwpGWy2wiwHdGcM5K7aZ.pdf.

24. Younis M, Jabr S, Al-Khatib A, Forgione D, Hartmann M, Kisa A. A cost analysis of kidney replacement therapy options in Palestine. Inquiry. 2015;52 https://doi.org/10.1177/0046958015573494.

25. Hutchison AJ, Courthold JJ. Enabling self-management: selecting patients for home dialysis? NDT Plus. 2011:4:iii7-iii10.

26. Bag E, Mollaoglu M. The evaluation of self-care and self-efficacy in patients undergoing hemodialysis. J Eval Clin Pract. 2010;16:605-10.

27. Clark-Cutaia MN, Ren D, Hoffman LA, Burke LE, Sevick MA. Adherence to hemodialysis dietary sodium recommendations: influence of patient characteristics, self-efficacy, and perceived barriers. J Ren Nutr. 2014;24:92-9.

28. Clark-Cutaia MN, Ren D, Hoffman LA, Snetselaar L, Sevick MA. Psychometric validation of the self-efficacy for restricting dietary salt in hemodialysis scale. Top Clin Nutr. 2013;28:384-91.

29. Kim JY, Kim B, Park KS, Choi JY, Seo JJ, Park SH, Kim CD, Kim YL. Health-related quality of life with KDQOL-36 and its association with self-efficacy and treatment satisfaction in Korean dialysis patients. Qual Life Res. 2013;22:753-8.

30. Krespi Boothby MR, Salmon P. Self-efficacy and hemodialysis treatment: a qualitative and quantitative approach. Turk Psikiyatri Derg. 2013;24:84-93.

31. Takaki J, Nishi T, Shimoyama H, Inada T, Matsuyama N, Kumano H, Kuboki T. Interactions among a stressor, self-efficacy, coping with stress, depression, and anxiety in maintenance hemodialysis patients. Behav Med. 2003;29:107-12.

32. Tanner JL, Craig CB, Bartolucci AA, Allon M, Fox LM, Geiger BF, Wilson NP. The effect of a self-monitoring tool on self-efficacy, health beliefs, and adherence in patients receiving hemodialysis. J Ren Nutr. 1998:8:203-11.

33. Wright LS, Wilson L. Quality of life and self-efficacy in three dialysis modalities: incenter hemodialysis, home hemodialysis, and home peritoneal dialysis. Nephrol Nurs J. 2015;42:463-76. quiz 77

34. Slesnick N, Pienkos S, Sun S, Doss-McQuitty S, Schiller B. The chronic disease self-management program - a pilot study in patients undergoing hemodialysis. Nephrol News Issues. 2015;29:22-3. 7-8, 30-2

35. Adas H, Al-Ramahi R, Jaradat N, Badran R. Assessment of adequacy of hemodialysis dose at a Palestinian hospital. Saudi J Kidney Dis Transpl. 2014; 25:438-42.

36. Al Zabadi H, Rahal H, Fuqaha R. Hepatitis B and C prevalence among hemodialysis patients in the West Bank hospitals, Palestine. BMC Infect Dis. 2016;16:41. 
37. Al-Ramahi R, Raddad AR, Rashed AO, Bsharat A, Abu-Ghazaleh D, Yasin E, Shehab O. Evaluation of potential drug-drug interactions among Palestinian hemodialysis patients. BMC Nephrol. 2016;17:96.

38. Naalweh KS, Barakat MA, Sweileh MW, Al-Jabi SW, Sweileh WM, Zyoud SH. Treatment adherence and perception in patients on maintenance hemodialysis: a cross-sectional study from Palestine. BMC Nephrol. 2017;18:178.

39. Zyoud SH, Al-Jabi SW, Sweileh WM, Tabeeb GH, Ayaseh NA, Sawafta MN, Khdeir RL, Mezyed DO, Daraghmeh DN, Awang R. Use of complementary and alternative medicines in haemodialysis patients: a cross-sectional study from Palestine. BMC Complement Altern Med. 2016;16:204.

40. Zyoud SH, Daraghmeh DN, Mezyed DO, Khdeir RL, Sawafta MN, Ayaseh NA, Tabeeb GH, Sweileh WM, Awang R, Al-Jabi SW. Factors affecting quality of life in patients on haemodialysis: a cross-sectional study from Palestine. BMC Nephrol. 2016;17:44.

41. Khatib ST, Hemadneh MK, Hasan SA, Khazneh E, Zyoud SH. Quality of life in hemodialysis diabetic patients: a multicenter cross-sectional study from Palestine. BMC Nephrol. 2018;19:49.

42. Raosoft. Sample Size Calculator. [cited 2016 September 23]; Available from: http://www.raosoft.com/samplesize.html.

43. Lorig KR, Sobel DS, Ritter PL, Laurent D, Hobbs M. Effect of a selfmanagement program on patients with chronic disease. Eff Clin Pract. 2001; 4:256-62.

44. Horowitz E, Abadi-Korek I, Shani M, Shemer J. EQ-5D as a generic measure of health-related quality of life in Israel: reliability, validity and responsiveness. Isr Med Assoc J. 2010;12:715-20.

45. Euro QOL Group EQ-5D-5L User Guide Basic information on how to use the EQ-5D-5L instrument. 2013 [cited 2015 April 1]; Available from: http://www. euroqol.org/fileadmin/user_upload/Documenten/PDF/Folders_Flyers/ UserGuide_EQ-5D-5L_v2.0_October_2013.pdf.

46. Callaghan DM. Health-promoting self-care behaviors, self-care self-efficacy, and self-care agency. Nurs Sci Q. 2003;16:247-54.

47. Kav S, Yilmaz AA, Bulut Y, Dogan N. Self-efficacy, depression and self-care activities of people with type 2 diabetes in Turkey. Collegian. 2017;24:27-35.

48. Wasserfallen JB, Halabi G, Saudan P, Perneger T, Feldman HI, Martin PY, Wauters JP. Quality of life on chronic dialysis: comparison between haemodialysis and peritoneal dialysis. Nephrol Dial Transplant. 2004;19:1594-9.

49. Roderick P, Nicholson T, Armitage A, Mehta R, Mullee M, Gerard K, Drey $N$, Feest $T$, Greenwood R, Lamping D, et al. An evaluation of the costs, effectiveness and quality of renal replacement therapy provision in renal satellite units in England and Wales. Health Technol Assess. 2005; 9:1-178.

50. Katayama A, Miyatake N, Nishi H, Uzike K, Sakano N, Hashimoto H, Koumoto K. Evaluation of physical activity and its relationship to health-related quality of life in patients on chronic hemodialysis. Environ Health Prev Med. 2014;19:220-5.

51. Javanbakht M, Abolhasani F, Mashayekhi A, Baradaran HR, Jahangiri noudeh $Y$. Health related quality of life in patients with type 2 diabetes mellitus in Iran: a national survey. PLoS One. 2012;7:e44526.

52. O'Reilly DJ, Xie F, Pullenayegum E, Gerstein HC, Greb J, Blackhouse GK, Tarride JE, Bowen J, Goeree RA. Estimation of the impact of diabetes-related complications on health utilities for patients with type 2 diabetes in Ontario, Canada. Qual Life Res. 2011;20:939-43.

53. Ayoub AM, Hijjazi KH. Quality of life in dialysis patients from the United Arab Emirates. J Fam Commun Med. 2013;20:106-12.

54. Pakpour AH, Saffari M, Yekaninejad MS, Panahi D, Harrison AP, Molsted S. Health-related quality of life in a sample of Iranian patients on hemodialysis. Iran J Kidney Dis. 2010;4:50-9.

55. Saffari M, Pakpour AH, Naderi MK, Koenig HG, Baldacchino DR, Piper CN. Spiritual coping, religiosity and quality of life: a study on Muslim patients undergoing haemodialysis. Nephrology (Carlton). 2013;18:269-75.

56. Manns BJ, Johnson JA, Taub K, Mortis G, Ghali WA, Donaldson C. Dialysis adequacy and health related quality of life in hemodialysis patients. ASAIO J. 2002;48:565-9.

57. Swaminathan S, Mor V, Mehrotra R, Trivedi AN. Initial session duration and mortality among incident hemodialysis patients. Am J Kidney Dis. 2017;70:69-75.

58. Eloot S, Van Biesen W, Dhondt A, Van de Wynkele H, Glorieux G, Verdonck $P$, Vanholder R. Impact of hemodialysis duration on the removal of uremic retention solutes. Kidney Int. 2008;73:765-70.

59. Marinovich S, Lavorato C, Rosa-Diez G, Bisigniano L, Fernandez V, HansenKrogh D. The lack of income is associated with reduced survival in chronic haemodialysis. Nefrologia. 2012;32:79-88.
60. Fiebiger W, Mitterbauer C, Oberbauer R. Health-related quality of life outcomes after kidney transplantation. Health Qual Life Outcomes. 2004;2:2.

61. Laupacis A, Keown P, Pus N, Krueger H, Ferguson B, Wong C, Muirhead N. A study of the quality of life and cost-utility of renal transplantation. Kidney Int. 1996;50:235-42.

62. Lev EL, Owen SV. A measure of self-care self-efficacy. Res Nurs Health. 1996; 19:421-9.

\section{Ready to submit your research? Choose BMC and benefit from:}

- fast, convenient online submission

- thorough peer review by experienced researchers in your field

- rapid publication on acceptance

- support for research data, including large and complex data types

- gold Open Access which fosters wider collaboration and increased citations

- maximum visibility for your research: over $100 \mathrm{M}$ website views per year

At BMC, research is always in progress.

Learn more biomedcentral.com/submissions 